\title{
A Preliminary Study on the Teaching Reform of Practice of Environmental Engineering for the Cultivation of Applied Talents
}

\author{
Xiaohui $\mathrm{Xu}^{1, \mathrm{a}^{*}}$, Jiexiong Zhong ${ }^{2, \mathrm{~b}}$, Lanhe Zhang ${ }^{1, \mathrm{c}}$ and Yunfen Shi ${ }^{1, \mathrm{~d}}$ \\ ${ }^{1}$ Northeast Electric Power University ,School of Chemical engineering, Jinlin Jinlin China; \\ ${ }^{2}$ CCCC Water Planning and Design Institute Co., Ltd., Beijing China \\ axuxiaohui06@126.com, ${ }^{b}$ herrick27@sina.com, ${ }^{\mathrm{C}}$ zhanglanhe@163.com, ${ }^{\mathrm{d}}$ shiyunfen0220@163.com \\ * the corresponding author
}

\section{Keyword: Environmental engineering; Practice teaching; Reform}

\begin{abstract}
In order to cultivate "applied talents", starting from the characteristics of professional training, dealing with the existing problems of environmental engineering specialty graduation practice, the countermeasures were taken by combining of on campus and off-campus mode practice, improving teaching resources and adjusting practice system and so on in this paper. The students' practical ability was effectively improved.
\end{abstract}

\section{Introduction}

Environmental Engineering is a new multidisciplinary cross-border integration of the emerging disciplines, which is a set of theoretical, technical, practical as one of professional. With the development of the society, the requirements of environmental engineering talents for their ability of application, innovation and comprehensive quality are also getting higher and higher. Practice is an effective bridge linking theory teaching and social practice. Practical teaching is to enhance students perceptual knowledge to consolidate and expand knowledge and skills, which could improve the ability to analyze and solve problems and cultivate students' innovative ability and comprehensive quality. In order to meet the needs of social and economic development and to cultivate a complex applied talents with a unified theory and practice, we must strengthen and attach importance to practical links.

Graduation practice is an important part of environmental engineering practice teaching after the completion of the syllabus for all professional courses. In practice, how to improve the quality of teaching practice and receive good teaching effects; how to assimilate the content of specialized courses into the actual position and on-site teaching in order to enable students to further consolidate and deepen the learned expertise; how to make the employer recognizing students' knowledge structure through practical training session; these questions must be seriously considered by our professional teacher.

\section{Problems of Environmental Engineering Practice}

In beginning of 2006, the first graduates from Northeast University of Electric Power Environmental Engineering worked in power plants. With the emphasis on environmental protection, the current power plant demands for environmental protection personnel more and more, and the setting of environment engineering in our university accorded with the demand of the power plant for environmental professional, so the graduation practice part of the profession must continue to practice and explore [1]. At present, the practice time is short, there are many problems that need to be solved, practice base is lack of, the practice method is single, and the practice can only be fully understood but not in-depth study, which results in many urgent problems to be solved in the practice [2].

Short Practice Time. Graduation practice is generally arranged in the third semester, practice time is 4 weeks, environmental engineering practice includes exhaust gas, waste water and waste treatment technology, involving a wide range of knowledge, but the practice time is short, making 
the practice ineffective [3]. At the same time, due to the short practice time, the students' mastery of the practice process knowledge is not deep enough.

Insufficient Teaching Resources. weak faculty

Since 2008, the number of annual enrollment doubled about 70 people. At the same time, due to the relative lack of teachers, each instructor-led practice students also increased significantly, and practice mentors are mostly young teachers who have little practice experience and are not familiar with the enterprise site, which is difficult for practice guidance tasks. These factors lead to a significant decline in the quality of environmental engineering practice. In addition, the tutor lacked the information communication with the enterprise technical staff before the practice, and the on-site teaching handouts were inadequately prepared. Enterprise staff usually follow the production process to lead students to visit and study, and can not achieve the desired effect of practice [4].

Inadequate practice base

Although enterprises and university can work together through science and technology projects, they can form long-term and mutually beneficial relations in terms of expanding social impact and obtaining outstanding graduates [5,6]. However, most enterprises think it is hard for students to practice short-term economic benefits and more worried about the normal production of the enterprises [7,8]. Enterprises in the preparation of on-site teaching handouts are not active, some of the information is not willing to provide guidance to teachers, explaining the content is casual, which result in large batches of students practice effect difference .

Insufficient apprenticeship

The practice funding of per student is less than 300 yuan in Northeast Electric Power University environmental engineering, including the recognition of practice, production practice, and practice weeks are 4 weeks. It is difficult to arrange students to stay in other provinces or practice of large-scale base, and the lack of practices often leads to the loss of remote base. For example, in 2013 , we practiced in Suizhong Power Plant, due to funding Seriously inadequate, round-trip tolls are unable to make ends meet, making the end of the practice base agreement. At the same time, due to our lack of practice funds, we can not choose medium-sized and large-sized enterprises with advanced technology and equipment, high automation and strict management as practices, which hinders students from learning more advanced practical knowledge. Therefore, practice funding is an important factor disturbing the practice of teaching, affecting the enthusiasm of teachers and students.

Single Practice. Many years ago, students were assigned to the production team to follow the class. Students could understand all aspects of production and had a deeper understanding of the production process, operating procedures, production processes, and pollutant treatment processes. Due to the gradual perfection of the safety management system at the higher levels of the practice units, the practice units hardly accept the practice mode of shift-based practice at the workshop of the students in the factory. Students' participation in practical work and equipment operation in the practice units becomes increasingly unfeasible. From the current form of practice, graduation practices have faded into awareness practices that take place at another time. The student just takes notes, only has a simple perceptual understanding and students have little or no prior knowledge of their expertise before the practice, or lack of prior knowledge of the companies to be interned, the students lack a deep understanding of the environmental engineering process, the structure and performance of environmental protection equipment, and the operational and operating conditions. Therefore, the effect of practice is poor.

\section{Practice Reform Measures}

Practice Mobilization to Improve Practice Enthusiasm. There are many safety issues in graduation practice, we must do well mobilization work before the practice. In the practice mobilization meeting, we should put forward the corresponding requirements to ensure the quality of practices. The most important thing is to carry out safety education to eliminate potential safety problems, to ensure the smooth progress of practices, to ensure practice goals. 
In the practice process, students with poor learning habits are less motivated to observe and take the initiative to think. In order to improve the students' enthusiasm for practice, the teacher advises the process and production status quo of different enterprises in advance and proposes targeted problems to be arranged as specific practice assignments to students. Students are required to observe the scene through technical observation, consult technical staff, who should study and analyze the theoretical knowledge conscientiously and solve the problem, who should carry out on-site practice with specific tasks. It is helpful to stimulate enthusiasm for practice, encourage to discover problems and ask questions for discussion so as to strengthen and consolidate the theoretical knowledge they have learned. Practice effect is improved[9].

Ensuring the Quality of Practice to Improve Practice Effects. Make full use of practice on campus

Due to short practice time, less practice base and insufficient funds, we need to make full use of practice on campus. According to environmental engineering training objectives, relying on the construction of environmental engineering and in the construction of specialties in the construction of a large number of laboratory equipment laboratory, our environmental laboratory have SBR reactor, UASB reactor, cyclone dust and tube electrostatic precipitator and so on. Some of the equipment is industrial equipment, and the other is made of plexiglass experimental equipment, whose internal structure we can see. According to the existing environmental protection equipment, we can establish perfect water, gas and solid environment purification technology for students to visit practices to make them have the practice conditions on campus to improve the practice effect. At the same time, we also base on the contents of professional experiments, designing a series of thematic or comprehensive engineering and research simulation projects, so that students can improve their practice and develop self-learning ability on the practice platform on campus[10].

Preferred on-site practicing environment.

Due to the small space on the production site, the number of interns that can be accommodated at the same time is also limited. If too many students in various positions affect the normal production of the enterprise, the scene noise is larger and the concentration of students is more intensive. Therefore, we can use the way of "decentralized practice". Students are divided into groups and each group does not exceed 15 people, according to the positions of students in stages rotation practice. This practice is more suitable for the actual situation of the production site, but also easy to instruct teachers to organize, manage and effectively guide students. Because the number of each group of students is small, everyone can hear and can participate in, there will be no phenomenon of students "slippery edge". In this situation we can choose quiet place for students to explain and solve student practices doubt [11].

collective discussion

In the process of practice, due to fewer instructors, it is impossible to conduct one-on-one counseling to explain. In addition, some students did not observe and understand the required process and equipment, nor did they have the ability to integrate theory with practice. In view of this situation, we can use a combination of on-the-spot study tour and group discussion. First, large group is divided into 4-5 groups with 3-4 members in each group. The team leader is responsible for explaining all the knowledge and the purpose is to master the practice contents by all the students. Second, everyone discusses the questions raised by the students collectively. Finally, the instructors evaluate and summarize for this situation.

Improving teachers' practical experience

In order to better ensure the quality of practices, colleges and universities should plan and purposely organize practice mentors to carry out business learning and send some teachers to train them. At the same time, teachers and enterprises should be strongly encouraged to conduct horizontal research projects for enterprises to solve some of the actual production problems. The mode of production, study and research can not only solve problems for enterprises, ensure the long-term stability of the production practice base, but also create favorable conditions for the scientific research in university. In order to improve the effectiveness of practice, the professional give full play to the experience of more experienced teachers. Under the guidance of their request, 
all new teachers completed a practice teaching, which improve the teaching effect of practice [12].

Improving the Practice of Assessment Methods. practice reply

The practice program uses a cyclical approach, taking full advantage of laboratory resources and giving students adequate practice space. After the practice on campus, students should be organized to reply in the form of ppt. Each group selected a representative as a presenter, the order of drawing lottery decisions, followed by the group to determine the principles of process, related equipment, principles and structure. Instructor asks questions, comments and suggestions for improvement.

Practice site test

In order to strengthen students' initiative in practice, in addition to discussing, but also for oral examinations, oral examinations are mainly to check the day or the previous day's practice. Each student have random questions for the practice site systems and equipment every day. In addition to deepening the student's impression of all knowledge, students can also increase your motivation to learn.

drawing paper

In the practice process, the drawing of paper for some of the key structures is another key factor in ensuring the quality of graduation practices[13]. For example, during an practice at a sewage treatment plant in Changchun, we demanded that the main single equipment diagram, floor plan, process flow chart and elevation map be drawn. During the drawing process, students found that there were still some problems that were unnoticed or ignored. Next day, they often took the initiative to go to the scene to observe carefully. Through these years of production practice process requires students to draw drawings found that students in the graduation design drawing ability, equipment selection ability, engineering ideas have been significantly improved.

practice examination

The contents of practice examination are both the details of the practice and a comprehensive summary of theoretical teaching. The papers include each detail, such as: writting out the practice in your choice of your process, the specific equipment structure and principles, in the practice process you have seen which pumps and valves and so on. These problems are not difficult, but are closely linked with reality.

\section{Conclusion}

We search for the appropriate training mode base on Environmental Engineering, choose practice of local enterprises and mobilize all the professional teachers to participate in and carefully organize the work. Through meticulous practice mobilization, it ensure the quality of the practice process, which combined with a variety of assessment methods to promote students' enthusiasm for practice In addition, paying more attention to the practice process, enhancing teachers' ability and team building, and providing financial and material resources help environmental engineering students have better improvement. Enhancing the quality of practices can achieve the combination of knowledge and engineering, at the same time, lay the engineering foundation for the practical application of professional knowledge. The implementation of these measures has greatly promoted the effect of practice, and enterprises have reached more than $95 \%$ satisfaction with student practices.

\section{Acknowledgements}

Jilin Province Institute of Higher Education 2017 Higher Education Research Project "Environmental Engineering Students Science and Technology Innovation Entrepreneurship Training and Construction" (JGJX2017D137);

Northeast Electric Power University Project "Environmental Engineering for Applied Talents Cultivation Practice Teaching Exploration" (JX201632). 


\section{References}

[1] Li Youping, Gao Cheng. Student-based Teaching Practice in Air Pollution Control Engineering[J]. Chemical Engineering Higher Education, 2012, 29(3): 103-105.

[2] Yang Zhen-guang. Construction of Outside-school Practice-base in Higher Learning Institutions[J]. Research and Exploration in Laboratory, 2011, 30(8): 366-368.

[3] Youping, Gou Xinglong, Liao Yunwen, et al. Problems and Countermeasures of Environmental Engineering Specialty Graduation Practice[J]. Experiment Science and Technology, 2015,13(1):149-151.

[4] Yan Dong-jie, Huang Xue-min, Yu Ya. A Research on the Quality Assurance Measures of the Production Practice of Environmental Engineering-A case study of the environmental engineering speciality in XAUAT[J]. J. Xi'an Univ. of Arch. \& Tech. (Social Science Edition), 2016,35(6):97-100.

[5] Zhang Bao-gang, Feng Chuan-ping, Kuang Ying, et al. On the Production Practice Mode of Environmental Engineering Practice under the Background of Excellent Engineers[J]. Chinese Geological Education,2013(4):9-12.

[6] Zhang Xuehong, Wang Dunqiu, Xu Jiangping, et al. Enhancing off-campus internship to bring up innovative environmental engineering talents[J]. Experimental Technology and Management, 2012, 29(7): 1-4.

[7] ]Yan Su-ding, Wang Dai-zhi, Tang Da-ping. Experiences and suggestions on environmental engineering practices in higher normal education[J]. Journal of Hubei Normal University ( Natural Science), 2012,32(2) :102 -104.

[8] Li Song, Song Zhaoliang, Chen Yonghua, et al. Teaching Reforms on Practices of Environmental Engineering Specialty Based on an Innovation Ability Training Mode[J]. Environmental Science and Management, 2010,35( 8) : 186-188.

[9] Liang Hong, Wang Bing, Xiong Ping. The Reformation and Discussion of the Production Practice for Environmental Engineering Major[J]. Journal of ChengDu Technological University, 2015,18(1):100-102.

[10] Shi Yun-fen, Xu Xiao-hui, Liu Li-dan, et al. Professional Practice Mode on Environmental Engineering with Characteristics of Power Plant Environmental Protection[J]. Journal of Northeast Dianli University, 2013,33(4):88-90.

[11]Chen Mei- qin, Wu Jing- xiong, Xie Wen- yu, et al. Training Mode Reform on Production Practice of Environmental Engineering with Petrochemical Background[J]. Education Teaching Forum, 2017(7):35-36.

[12] Xie Yu, Song Weijun . Teaching Exploration and Practice about off-campus Internship in Environmental Engineering Specialty Under the context of cultivating Applied Talents[J]. Journal of HeiHe University, 2016(7):94-98.

[13] Song Yong. Teaching Experience of Environmental Engineering Specialty in the Specialized Production Practice[J]. Guangzhou Chemical Industry, 2015, 43(22):235-236. 